\title{
Issues on Business Vocabulary Acquisition by Russian Tertiary ESP Students
}

\author{
Natalia Troufanova \\ PhD in Philology, Associate professor, Head of L-2 Dpt., Bauman Moscow State Technical University \\ 5 (bld.1), 2nd Baumanskaya str., Moscow, Russia, 105005; ntroufanova@mail.ru
}

\section{Kira Inozemtzeva}

PhD researcher, senior lecturer at L-2 Dpt., Bauman Moscow State Technical University, Moscow, Russia 5 (bld.1),2nd Baumanskaya str., Moscow, Russia, 105005; Kira.inozemtseva@yandex.ru

\section{Doi:10.5901/mjss.2015.v6n6s5p242}

\begin{abstract}
The present paper examines key issues regarding the differences in structural and semantic characteristics of economic term systems in Business English and Russian, which pose major translation challenges and cause problems in intercultural professional communication. Difficulties in vocabulary acquisition caused by non-equivalence in Russian and English business lexis are analyzed. The article attempts to describe some common types of non-equivalence caused by lacunas, nonequivalent words and culture-specific words in Business English. As the infusion of English vocabulary into contemporary Russian is rapid and widespread, many recent borrowings have several variants of spelling, being either exact transliteration or having modified spelling assimilated to the Russian language patterns. The article emphasizes the importance of differentiated approach to the identification, selection and arrangement of the lexical material. Contrastive sociolinguistic research aimed at revealing some common and distinguishing features in the terminological competence of the Russian and English-speaking business communication participants is described. The implications of business vocabulary acquisition for the formation of intercultural professional communicative competence of Russian ESP economics students are highlighted.
\end{abstract}

Keywords: ESP, terminology, business vocabulary, vocabulary acquisition, borrowings, sociolinguistics.

\section{Introduction}

After several decades of intense development, internationalization of higher education has grown in scale and value. The centrality of this idea in Russia is emphasized in national policy statements, international declarations and university strategic plans.

According to J. Knight, internationalization of higher education is "the process of integrating international, intercultural and global dimensions into goals, functions and processes of higher education" (Knight, 2012). This process has changed perception of what English language competence means for a specialist in a globalized world. Building relationship between countries, people, cultures, institutions and systems is much dependant on effective communication that requires high level of English language proficiency in the field of the participants' specialism.

Despite emphasis put on recognition of top Russian universities by international ratings, academic activity and international citation level of Russian scientists are still insufficient. Besides, just a small number of Russian economists integrate into the world professional community, although innovative development of Russian economy according to international standards is a top priority of the country's national policy. Stakeholders of internationalization process lay the responsibility for low level of Russian specialists' integration into the global professional and scientific communities upon the level of ESP teaching at Russian universities.

In order to strengthen tertiary ESP training, Russian ESP educators teaching business and economics students have to be able to prove their expertise in constantly evolving special vocabulary, that is one of major challenges both for Russian students and for ESP teachers. ESP teachers have to extend their awareness of the issues touched upon during business and economic classes. Most ESP teachers have a language teaching background with no first-hand experience of the content and context of business. Acquiring knowledge of business and economic vocabulary comes from reading authentic journals, books, watching business news, talking with business professionals and cross-disciplinary cooperation of Linguistics and Business departments.

Despite cross-disciplinary character of ESP as a discipline integrating language and specific content, the meaning 
of linguistic research carried out by ESP teachers in the field of terminology cannot be underestimated in the context of teaching business and economic vocabulary. Drawing on their wide experience as ESP educators, the authors explored an extensive number of business terms from two interrelated perspectives: the origin and functioning of the above lexis in various business contexts and their acquisition by university students with a view to overcome difficulties in their professional communication and job-relevant translation. The data obtained during this research can contribute to design of an ESP syllabus targeted at developing ESP competence of an international business specialist. The above data can also help ESP educators in teaching subject-specific writing in the field of business and economics; as well as they might be used by economic scientists for scientific writing purposes.

\section{Linguistic Characteristics of Business English Vocabulary}

One of the most important factors to be taken into account in teaching and learning business-specific vocabulary is the stylistic variation in $\mathrm{BE}$, as some formal words are used predominantly in written discourse while others mostly occur in spoken or conversational BE.

In some recent studies, Business English Corpus data are exploited to study genre and register variation (James \& Purchase, 1996; Curado Fuentes, 2000). Lexical diversity is found in email writing, which features words and phrases that can either resemble conversational input or provide dimension that is closer to academic writing. James and Purchase (1996) describe a study concerning the choice of Economics and Business Science Vocabulary at the university level for teaching purposes. They analyze the terms borrowed from specialized technical fields and select key vocabulary according to the frequency and dispersion of subject-based lexical items in textbooks.

The use of business vocabulary in different interconnected spheres of business leads to a significant degree of polysemy and synonymy in naming of economic concepts. Radosavljević (2010) discusses the problem of 'multimeaningfulness' in BE vocabulary. The study suggests that teachers and learners of BE should know the specific professional meaning of business terms, understand the professional knowledge and build context-awareness to exclude 'multiminingfulness' and ambiguity.

The heavy use of buzzwords, neologisms as well as a large number of metaphors and idiomatic expressions represent a distinguishing characteristic of business discourse and cause a burden for economics students and their language advisors. In business dictionaries, many of them are labelled as informal, yet many are not restricted to colloquial contexts and may be used in written texts, such as articles on venture capital financing.

The use of metaphoric expressions in the field of economics has received much attention. Several studies attempted to uncover conceptual metaphors in particular sectors of business journalism and establish conditions under which enhanced metaphor awareness is beneficial to learners' vocabulary expansion (Boers, 2004, Koller, 2004). According to Boers and Demecheleer (1997), typical metaphorical themes in economics are Mechanisms and Machines (fine-tuning economic growth), Animals (seagull manager, loan shark), Plants and Gardening, Health and Fitness (company doctor, financial injection), Fighting and Warfare (conquer the market), Ships and Sailing (to be on the rocks, to rock the boat), and Sports (in pole position). Though most linguists agree that metaphors should be included in BE syllabuses, it is still not entirely clear which metaphors should be taught and 'how much metaphor instruction is needed to yield long-term gains in learners' vocabulary expansion' (Boers, 2004, p. 228).

Another notable feature of economic terminology and business jargon is the common use of all types of abbreviations, such as initialisms (APR, GDP, PLC), acronyms (SWOT analysis, ROI), clippings (Inc., ad/advert, Rep), and blends (glocalization, infomercial, flexecutive). Pop and Sim (2009) tried to provide an insightful analysis of some of the acronyms and initialisms used in BE. However, the techniques of teaching commonly used abbreviated forms of business lexical units remain to be discussed, as they appear quite frequently in BE articles and cause major difficulties in terms of decoding and translation.

\section{Difficulties in Vocabulary Acquisition Caused by Non-equivalence in English and Russian Business Lexis}

Russian students of economics are taught various strategies to ensure better reading comprehension by using a number of content clues. There is an almost unlimited variety of clues possible, such as description clue, contrast clue, cause and effect clue, synonym restatement, exemplification, analysis of morphological structure etc. Although the learners are encouraged to develop this key vocabulary skill of guessing a new term's meaning from the context, it is a slow and complicated process, which can be completed only as a whole-group activity. In their autonomous work, students are often reluctant to use this elaborate and time-consuming procedure.

A relatively small number (about 20\%) of students turn to business dictionaries for learners of English to find the 
definitions of unknown terms. The majority of students prefer to use English-Russian business dictionaries. There have appeared a few up-to-date and comprehensive bilingual dictionaries covering all the latest business terms. However, these dictionaries are far from being concise and perfect, as the challenges in translation that ESP lexicographers face at present are similar to the difficulties that learners of BE encounter quite often.

Translation challenges are believed to be linked with the problem of non-equivalence. A number of significant factors that lead to non-equivalence in economic discourse have been highlighted; the most crucial of them are discussed below.

1. English business terms may express a concept, which is culture-specific and unfamiliar to the Russian speakers. For example, stockjobber is a British-specific term for 'someone whose job was to buy stocks and shares dealing only with brokers and not directly with investors'.

2. There may be different distinctions in meaning of translational counterparts, which lead to lexical discrepancy. In this case, a common problem, which constitutes a real area of difficulty that Russian students encounter with BE vocabulary, is that a Russian lexeme has two or more counterparts. English, for instance, has two nouns, salary/wages and amortization/depreciation, and two adjectives, effective/efficient, that correspond to the Russian words 'zarplata', 'amortizacija' и 'effektivnyj' with the broader meaning.

In some cases there may be several words in Russian that are close in meaning, but the corresponding lists of English synonyms and words related in meaning is much longer. For instance, in Russian we usually use the words 'uvolit", 'otstranit", 'sokratit", which mean 'be remove from job or responsibility', whereas in English students have to choose between dismiss, discharge, fire, sack, lay off, and make redundant, which have either semantic, stylistic or dialect differences.

3. English language terms may be semantically complex or not lexicalized in Russian. For example, absenteeism - 'a problem of employees not being at work when they should be' seems to be universal but there is no particular term to denote this concept in Russian.

It is worth mentioning that these lacunas are being increasingly filled in with English loan words. Some of the most frequently used borrowings include: futures / 'f'juchersy', derivatives 'derivativy'l, default / 'defolt', trader / 'trejder', securitization / 'sek'juritizacija', bidder / 'bidder', overdraft / 'overdraft', stakeholder / 'stejkholder', hedge / 'hedzhirovat", etc. Most of these newest business loanwords denote economic concepts, which were not lexicalized in Russian until 1990s.

Krysin (2004) sees both linguistic and socio-psychological reasons for this tendency, such as:

- $\quad$ the absence of the native language equivalent for a new concept;

- concretization and specification of certain concepts by denoting them with different lexemes ('servis' (service) -' obsluzhivanie', 'eksport'(export) -'vyvoz');

- tendency to use one borrowed word instead of a descriptive clause in the native language;

- higher prestige of lexical borrowings; communicative relevance and formation of international jargon (Krysin, 2004: 188).

Although some linguistic conservatives may voice their negative attitude towards Anglicisms, others think they provide an advantage in lexical competition because they make economic terminology more homogeneous. At the same time, such "international" terminology creates considerable difficulties in vocabulary acquisition because Russian students may translate business-specific terms easily replacing them by similarly sounding loan words, but they sometimes have no idea what meanings are.

4. A Russian language term may have the same denotation as the source language word, but it may not possess same emotional connotation. The difference may be obvious or subtle, but important enough to pose a problem for students in a given context.

This is particularly the case with the metaphorical expressions, for example, rainmakers and sunrise industries. Both possess positive emotional connotation, while their Russian equivalents 'lobbist' and 'novye otrasli ekonomiki' do not.

Apart from the possible difference in the expressive meaning, such lexical units cause major difficulties in acquisition by Russian students because their metaphoric meanings were established in a foreign language and the underlying associations and comparisons may be unclear to them.

The practical problem-solving approach to teaching non-equivalent terminological vocabulary to ESP students is to translate by paraphrasing on the base of super-ordinate or related terms. Translations by means of loan words and calqued lexemes when they occur for the first time should be supplemented by explanations, descriptions and illustrations to convey the terms' precise meanings. 
As for the culture-specific vocabulary, this may be a fruitful area for comparisons with the student's first culture and target economic patterns. In this case the foreign language teachers help the students to create bridges from one cognitive system to another.

\section{Contrastive Sociolinguistic Study of Anglicisms and their BE Prototypes}

This study investigated some similarities and differences in the terminological competence of Russian and Englishspeaking business communication participants. It analysed conceptual knowledge and the actual usage of both lexical borrowings and loan translations as well as their equivalents in the source language. The implications for teaching and learning English business vocabulary are discussed.

\subsection{Aim}

As it was stated above, the emergence of English as a world language has promoted regular economic contacts between two countries with hundreds of Anglicisms becoming an integral part of the Russian financial and economic terminology and business jargon.

The consequences of such a massive invasion of foreign language nominations in the Russian language system are complex semantic processes that occur during their adaptation. These include acquiring both additional meanings and new connotations.

Empirical evidence shows that the meaning of some loanwords remains unknown or inaccurately understood by many Russian speakers, even those who have sufficient professional experience in the field of economics and business. The improper usage of lexical borrowings and loan translations can lead to communicative failures in business communication.

Thus, BE vocabulary is a promising area for a contrastive sociolinguistic research, adequately demonstrating all phases of communication: the usage of the terms in their native language environment - through a complex mechanism of integration - to the inclusion in the dictionary of the Russian language, i.e. to the final stage of their adaptation. This aspect involves a comparison of nominative ESP units not only on the semantic level, but also on the communicative one.

The purpose of this study was to carry out a contrastive analyses of lexical and conceptual knowledge of a number of recent lexical borrowings in the field of business and economics and their BE equivalents. In other words, it aimed at revealing some common and distinguishing features in the actual usage of Anglicisms and their prototypes in the Russian and English language business communication.

From the pedagogical perspective, students' awareness of difference in the usage of terminological counterparts may be enhanced by comparing their own meaning representations with native-speaker information.

\subsection{Participants}

The 60 participants were Russian-speaking business graduates who are current employees of Moscow companies. Almost the same number (58) of English-speaking economists participated in the study, including 32 Americans, 23 British and 3 Canadians educated in the English-speaking countries and employed by Russian (7), British (20) and American (31) companies. Most of the informants were involved in Banking and Finance (33/24), Risk Management and Insurance (16/12), Sales and Marketing (4/22) and Industrial Logistics Management (7 Russian economists). Their ages ranged from 20 to 36 years, thus representing the most professionally active part of population.

\subsection{Target Lexical Items}

The lexical items selected for the business language questionnaire were lexical borrowings of agent nouns and their English equivalents, denoting persons or companies. 'Borrowed agent nouns' refer to a set of lexical items, which are essential and relatively frequent in economic articles. Some of them are well-known and widely used, for instance: 'broker' (broker), 'diler' (dealer), 'distribjutor' (distributor), 'menedzher' (manager). Other borrowed terms ('stejkholder' (stakeholder), 'frilanser' (freelancer), 'bajer' (buyer), 'promouter' (promoter), etc.) are covered by most Russian dictionaries of economic and business terms but seem to be restricted by the boundaries of professional vocabulary usage. A corpus search of the modern Russian language (www.ruscorpora.ru) incorporating over 300 million words indicates that these lexemes appear not very frequently in the general language. It gives a relatively small number of results for each of them (for example, 'distribjutor' - 59 documents, 79 contexts, 'promouter' - 10 documents, 18 
contexts, and 'frilanser' - 3 documents, 3 contexts).

A small group of lexical units were metaphoric expressions used to refer to persons in economic discourse. As I have already noted, they were borrowed from English by literal word-for-word translation, for example: «byk» / bull, «biznes-angel» / business angel, «chernyj rycar'» / black knight, «doctor kompanii» / company doctor, «akcionerdissident» / dissident shareholder, «raketnyj uchenyj» / rocket scientist.

\subsection{Procedure}

The data referred to here come from business language questionnaires distributed via email over the period of the past two years. Each participant was sent a list which included 23 lexical units denoting persons. In the first part of the questionnaire, they were asked to fill in the information about their age, education and area of work. In the second part, they were asked to define specific terms by answering two questions:

1) Are the following terms familiar to you? Please tick the boxes.

2) If you know the term, please use the large box to define the word, or provide a word or expression with a similar meaning.

All the questions were given in their native languages and the participants responded in their native languages as well. They were asked to answer the questions independently, without any consultation or lexical reference.

Data processing was based on the methods of quantitative and component semantic analysis with the following description, generalization and comparison of the results.

\subsection{Meaning representation strategies}

The definitions the respondents gave included a great deal of professional knowledge. Basic ways (strategies) of meaning representation used by both groups of participants are listed below. Russian-speaking participants' sample answers are given in translation.

1. The definition of the term: dealer / 'diler'

- a person who is buying and selling goods or services for profit (Russian-speaking informant- RSI)

- someone who purchases and maintains an inventory of goods to be sold (English-speaking informant $\mathrm{ESI})$

2. Synonym replacement and cross-reference to one of the terms listed in the questionnaire: dealer / 'diler'

- broker/trader, foreign exchange trader (ESI) ретейлер / retailer

- similar to a broker or agent (ESI)

- $\quad$ seller (RSI)

3. Indication of the professional business sphere in which the term is used: «byk» / bull

- a stock-market term (ESI) провайдер / provider

- a person or company that provides a service. It is frequently used in health care to refer to hospitals (ESI)

4. The term's context usage examples: «raketnyj uchenyj» / rocket scientist

- $\quad$ is usually used in the phrase, "you don't need to be a rocket scientist to understand or do something (ESI)

- normally, used in the negative - "it is not rocket science" - "you don't need to be a rocket scientist to " meaning you don't have to be super bright to understand a new situation or job or instruction (ESI)

5. Marking some terms as restricted to one of the regional dialects (by English-speaking participants): 'komplaens-kontroler' / compliance controller

- possibly an Americanism - Quality Controller in English. A person who is responsible for maintaining the level of service or manufacture to agreed standards

- 'stok-dzhobber' / stock-jobber

- British English?

6. Reference to the source language (by Russian participants): "/ scalper

- I haven't heard this word in Russian. In English it usually refers to someone who buys tickets to events and then "scalps" them for a profit «бык» / bull

- translated from English - a person who counts on the growth of share prices on the stock market 


\section{Illustrative explanations: 'reider' /raider}

- I think it is someone who is engaged in buying the company's assets in order to destroy and resale it subsequently (Richard Gere's character in "Pretty Woman") (RSI)

- Rosneft company - it forced Yukos into bankruptcy and took over its assets (RSI)

\section{Results and Discussion}

The results of the study revealed some common and distinctive features in the terminological competence of Russian and English-speaking participants. Almost half (11) of the loanwords adopted by the Russian language and their English counterparts were familiar to both groups. Thus, lexical items denoting equally relevant concepts for both groups of informants include: 'broker' (47) /broker (43), 'brjend-menedzher' (43) / brand manager (36), 'diler' (50) /dealer (36), 'developer' (39) / developer (45), 'provajder' (47) /provider (32), 'retejler' (34) / retailer (40), 'trejder' (42) / trader (44), 'distribjuter' (26) / distributor (29), 'frilanser' (33) / freelancer (38), 'promouter' (26) / promoter (20), 'merchandajzer' (21)/ merchandiser (27) (in parentheses is the number of informants who use the term quite frequently or sometimes). However, the participants pointed out different semantic components in some of them. Thus, the English speaking economists described broker as a person who buys and sells either goods, or services or shares, business interests, real estate, securities or other commodity, whereas for the Russian economists the main semantic component in the meaning of the word broker was not the object a broker deals with, but his place of work which most of them indicated as a stock exchange. This may be the reason why the real estate broker would be most likely translated into Russian as 'rijeltor' (realtor).

Idiomatic expressions which are widely used by both English-speaking and Russian business journalists turned out to be vaguely familiar to both groups of economists, though a few English-speaking participants managed to guess the meanings of some of these idioms correctly. Interestingly enough, their Russian colleagues were unable to make accurate guesses about the meanings of most of business idioms and marked most of them as unknown.

The only metaphoric unit, which is quite familiar to the economists of both groups was «byk» / bull. $17 \mathrm{RSI} / 12$ ESI have come across this term, but do not know what it means, 5 RSI / 14 ESI know this term, but never use it and 3 $\mathrm{RSI} / 10 \mathrm{ESI}$ occasionally use this term.

Four lexical units which were on the list seemed more familiar to the English respondents, as they have appeared in Russian quite recently and most of them denote area-specific concepts, such as scalper, stakeholder, compliancecontroller and buyer.

An unexpected result of the study was that two words turned out to be more familiar to the Russian business graduates. These are the words 'rejder' / raider - a term denoting a "an individual or corporate investor who intends either to take control of a company by buying a controlling interest in its stock and installing new management, or to make a quick profit by threatening to take control and selling the stock back" and 'grinmejler' / greenmailer - used for people and companies trying to buy their "stock from a suitor, often for a very high price, to try to prevent a takeover" . A quick Google search for these loan words in Russian produces quite a list of results (1 100000 for 'rejder' and 6810 for 'grinmejler'). Presumingly, these concepts are essential for the Russian economic situation at present.

The analysis of interpretation provided by the participants of both groups shows that approximately a quarter of the terms are interpreted in an identical fashion. National component is manifested in revealing various distinctive components denoted by associations of concepts based on real-world business experience and knowledge. Most difficulties were caused by polysemous words used to talk about different business subjects. For example, fewer than half of Russian respondents (23) and 16 English-speaking informants, including almost all experts in the field of transport services, express delivery and logistics, use the term provider in a broad, industry-general meaning; in most cases it is synonymous with the term supplier:

- $\quad$ an organization that provides goods and services (RSI)

- a legal entity carrying out the supply of material resources or the provision of services on a contract basis (RSI)

- $\quad$ the service provider (RSI)

- $\quad$ supplier (RSI)

- supply company (RSI)

- person/organization/company providing service (ESI)

- a company that supplies products or provides services for a particular group or in a particular area (ESI) 
- a person or organization who takes responsibility for the provision of goods or services on behalf of other (ESI)

Only several of the Russian participants (8) gave a more narrow interpretation of the term:

- a company that provides access to the global use of Information Systems, the Internet

- a company that provides access to Internet resources via a modem or high-speed technologies (ISP)

Typically, Russian-speaking informants provided a "combined" definition, incorporating both general business meaning and the explanation that the term may be used when talking about a particular subject, i.e:

- a company that provides any services, most of all - a company that provides users with access to the Internet (e-mail hosting) - a legal entity that provides certain services, for example, the Internet telephony

English-speaking respondents followed the same strategy, though indicating several business areas where this term might be used:

- a person who provides a service, this term is widely used for those who provide internet access;

- a company that provides services; Internet Service Providers

- a person or company that provides a service. It is frequently used in health care to refer to physicians or hospitals;

- a person that provides a good or service. Often used to describe physicians as 'providers' of health care.

Thus, the interpretation of the term's general business meaning can be considered similar, while its narrow industry-specific representations differed considerably.

Similarly, unlike most English-speaking respondents who are more-or-less familiar with the meanings of polysemous terms, Russian participants tended to define several of them in only one area-specific context. For instance, most of them use the word 'developer' (developer) to denote 'company whose business is buying land and building on it' and the word 'stejkholder' (stakeholder) as a synonym of the word shareholder, being unaware of their other senses.

To sum up, Russian business graduates sometimes cannot accurately determine the meaning of lexical borrowings or have a different understanding of the economic concepts that are denoted by the borrowed terms.

Naturally, this approach to terminological meaning determination cannot ascertain specialist conceptual knowledge to its full extent, as it does not allow the terms to activate the full resources of their meanings. Although word meanings may give some sense of a word's meanings, context plays a large part in filling in the other information necessary to make use of that word. Therefore, a detailed sociolinguistic analysis of the actual usage of vocabulary, which may consider cultural and situational context in which economic terms' meanings emerge, is required. This may help to determine whether the meaning of certain loan words and their counterparts are similar or significantly/slightly different.

\section{Conclusion}

In this article, a broad range of issues have been briefly introduced including the differences in structural and semantic characteristics of economic term systems in Business English and Russian, which pose major translation challenges and cause problems in vocabulary acquisition. Some problems confronting economics students and their ESP teachers may be common for ESP students of other countries, as English is a global lingua franca used in business communication today. Difficulties encountered by Russian learners, as reported in empirical studies, show that the main pedagogical emphasis should be put on showing connections between the same business term or similar words used in different contexts and situations. The cross-disciplinary approach, which implies compacting of the curriculum in both English and Economics subjects, is supposed to enhance the effects of ESP instruction.

Apart from the challenges in vocabulary acquisition caused by disciplinary and stylistic variation in $\mathrm{BE}$, many problems are connected with the integration of the newest Anglicisms into Russian business and economic terminology. Typically, most of the new borrowings do not have corresponding equivalents in contemporary Russian and explanatory translations in this case might be the only option, as students find it extremely difficult to determine their meanings.

To get a real picture of the impact of Anglicisms on contemporary business Russian in the context of dynamic communication process, a contrastive sociolinguistic study was carried out. It aimed at revealing some common and distinguishing features in the actual professional usage of lexical borrowings or loan translations denoting persons and their English-language prototypes. The terms were sorted into categories according to the frequency of usage and meaning representation strategies chosen by the informants of each language group. The reasons of lexical-semantic loan words, as well as specific communication problems arising because of violating the necessary correlation between the native and borrowed resources of language were examined, and the possible methods for their solution are briefly discussed. 
At present, methodologists focus on developing student's vocabulary by incorporating readings from a variety of sources and exercises with business-specific terminology. At the same time, university language advisors often find themselves working as ad hoc terminologists and terminographers to help students acquire specialist lexis that they may need. The problem of compiling a bilingual business language dictionary for upper-intermediate Russian learners of English is urgent and practical today, although it has not received much attention up to the present.

The study also identified the need to make classroom applications aimed at the organization of business vocabulary in such a way that it will give students insight into the field of economics from the native speaker's view. Such experience may be therefore necessary as not only the culmination of content and language learning, but also the development of intercultural professional communicative competence. Linguistic, sociolinguistics and corpus linguistics analyses should be considered in developing such applications.

\section{References}

Boers, F. and Demecheleer, M. (1997) A few metaphorical models in (western) economic discourse. In: W. Libert, G. Redeker and L. Waugh (eds.) Discourse and Perspective in Cognitive Linguistics (pp. 115-129). Amsterdam/Philadelphia: John Benjamins.

Boers, F. (2004). Expanding Learners' Vocabulary through Metaphor Awareness: What Expansion, What Learners, What Vocabulary? In M. Archard and S. Niemeier (eds.) Cognitive linguistics, second language acquisition, and foreign language teaching. Berlin, Germany: Mouton de Gruyter, 211-232.

Curado Fuentes, A. (2000). Exploitation and assessment of a Business English corpus through language learning tasks. [Online] Available: http//www.uni.no/icame/ij26/curadofuen.pdf. (September 20, 2015).

Knight, J. (2012). Five truths about internationalization. International Higher Education. Boston College Magazine. Fall 2012. № 69. [Online] Available: http//www.bc.edu/cihe. (September, 20, 2015).

James, G., Putchase, J. (1996). Corpus-based Lexical Analysis of English in Business Studies and Economics. Hong Kong: Hong Kong University of Science and Technology.

Koller, V. (2004). Metaphor and Gender in Business Media Discourse: A Critical Cognitive Study Description. Basingstoke: Palgrave Macmillan.

Krysin, L.P. (2004). Inoyazychnoe slovo v kontekste obshchestvennoi zhizni konza XX veka. Russkoye slovo, svoye i chuzhoye. Moscow: Yazyki slavyanskoy kultury.

Pop, Anamaria M., Sim, Monica A. (2009). The use of Acronyms and Initialisms in Business English. Annals of the University of Oradea, Economic Science Series 18 (1), 557-562.

Radosavljević, M. (2010). Contrastive View of Polysemous and Homonymous Terms in Business English Jargon. [Online] Available: http://www.civitas.fpps.edu.rs/03/article/pdf/Civitas03_article03.pdf. (September, 20, 2015). 